\title{
Survey of Low Birthweight and Extremely Low Birthweight Events in a High Environmental Risk Area of Apulia, Italy
}

\author{
Paolo Trerotoli ${ }^{1}$ ([) $\cdot$ Nicola Bartolomeo ${ }^{1}$ (i) $\cdot$ Simona Leogrande $^{2} \cdot$ Sabrina Triggiani $^{1} \cdot$ Antonella Mincuzzi $^{2}$. \\ Gabriella Serio $^{1}$ (1) Aldo Sante Minerba ${ }^{2}$
}

Received: 9 July 2020 / Revised: 9 September 2020 / Accepted: 5 October 2020 / Published online: 12 November 2020

(c) The Author(s) 2020

\begin{abstract}
The association between environmental conditions and pregnancy outcome has been under investigation for a long time, but results appear to be inconclusive regarding damage to either the newborn or the mother. The aim of this study was to evaluate the distribution of hospitalization of newborns with low birthweight $(<2500 \mathrm{~g})$ and extremely low birthweight $(<1000 \mathrm{~g})$ in the geographical area of Taranto, Italy, which is characterized by high environmental risk because of industrial pollution. We analyzed the database of hospital discharge forms for the years 2001-2013 regarding hospital admission of newborns in the region of Apulia. The relative risk (RR) of hospitalization, adjusted for the deprivation index, was estimated using the Besag-York-Molliè Bayesian model. The city of Taranto, which has the highest environmental risk, had the highest RR for newborns with low birthweight (1.47, 95\% uncertainty interval 1.38-1.56). Other geographical areas with high environmental pollution had higher RRs for low birth weight compared with the regional average. We found no geographical distribution pattern of extremely low birthweight that would suggest an association with environmental pollution.
\end{abstract}

Keywords Environmental risk · Bayesian model · Low birthweight

\section{Introduction}

Birthweight less than $2500 \mathrm{~g}$ (low birth weight, LBW) or less than $1500 \mathrm{~g}$ (very low birth weight, VLBW), small for gestational age fetus (SGA), and intrauterine growth restriction (IUGR) are pregnancy outcomes that can predict newborn health. The rate of LBW in Western countries is $6 \%$ (United Nations 2004) and 7.4\% in Italy. According to a recent report on birth and pregnancy; the rate of VLBW in Italy is $1 \%$ (Basili et al. 2018). It has been observed that mortality and morbidity within the first 30 days after delivery of a VLBW newborn are higher than that of other neonates (O'Leary

Paolo Trerotoli

paolo.trerotoli@uniba.it

Simona Leogrande

simona.leogrande@asl.taranto.it

1 Department of Biomedical Science and Human Oncology, University of Bari Aldo Moro, Piazza G. Cesare 11, 70124 Bari, Italy

2 Statistics and Epidemiology Unit, Taranto Health District, Viale Virgilio 31, 74121 Taranto, Italy et al. 2017), especially in developing countries where there is a greater frequency of LBW infants (Lee et al. 2017).

LBW can predict a greater need for hospital care, with higher costs for care; therefore, cost-benefit analyses are needed to evaluate actions and decisions regarding prevention of this pregnancy outcome. In particular, preterm VLBW infants need more care than other LBW newborns (Cavallo et al. 2015). Interventions targeting health-related habits in the mother that are risk factors for pregnancy and for the fetus have not reversed the cost of care; in fact, prevention has often been more costly than infant care (Almond et al. 2004).

According to many authors, environmental pollution is considered an important risk factor that is unrelated to the mother's health habits. Researchers believe that environmental policies that can reduce exposure to this risk factor could have a beneficial effect on pregnancy as well as preventing other diseases. For example a review including 41 studies found an association between sulfur dioxide and preterm birth, as well as an association of particulate matter (PM) with preterm birth and SGA. However, the same review found no association between pregnancy outcomes or newborn health and other oxides like nitric oxide (NO), 
nitrogen dioxide $\left(\mathrm{NO}_{2}\right)$, ozone $\left(\mathrm{O}_{3}\right)$, and carbon monoxide (CO) (Shah et al. 2011).

A 2012 metanalysis evaluated the association between $\mathrm{CO}, \mathrm{NO}_{2}, \mathrm{PM}$, and LBW in newborns, and air pollution was found to be a significant risk factor. In particular, the pooled odds ratio suggested $\mathrm{CO}, \mathrm{NO}_{2}$, and $\mathrm{PM}$ with diameter $\leq 10 \mu \mathrm{m}$ (PM10) were associated with a risk for LBW and these were strong risks factors for preterm birth (Stieb et al. 2012). Another metanalysis found no relationship between mortality in newborns or pregnant woman and environmental pollution, but an increased risk of LBW, IUGR, and malformation associated with environmental pollution was found (Kihal-Talantikite et al. 2017).

Apulia is a geographical area in the southern part of Italy that comprises large industrial areas with steelworks and chemical production. These are mostly located in the county of Taranto on the Ionian Sea and Brindisi on the Adriatic Sea. Taranto is included as a site of national interest for surveillance of environmental pollution and increased cancer incidence (Mataloni et al. 2012). Since 2007 Regional Environmental Protection Agencies have monitored pollutants finding critical levels especially for PM10, dioxin and benzopyrene (Mincuzzi et al. 2013). The last Report on Air Quality in Apulia has shown for the area of Taranto an annual mean concentration of $20 \mu \mathrm{g} / \mathrm{m}^{3}$ for PM10 and 10 $\mu \mathrm{g} / \mathrm{m}^{3}$ for PM2.5 (Development Team 2014). Taranto's local managers are encouraging continuous surveys of population health status to evaluate and rapidly detect increases in various diseases, including cancers. Several research works have been funded to evaluate temporal and spatial trends of diseases in Taranto (Mincuzzi et al. 2013; Minerba et al. 2018).

In this paper we report the results of the analysis of hospital discharges for preterm infants with LBW and extremely LBW (ELBW) in the high environmental risk area of Taranto and in the whole Apulia, to evaluate association between pregnancy outcomes and environmental pollution.

\section{Materials and methods}

The present analysis included all births in Apulia from 01/01/2001 to 31/12/2013. Data were extracted from the Hospital Discharge Form Data Base (HDFDB) for residents of Apulia admitted to hospitals both within and outside Apulia. Information was collected from two different databases for hospital admissions inside and outside the Apulia region; these data were normalized and merged.

LBW newborns in the HDFDB were identified according to the primary diagnosis or a secondary diagnosis using International Classification of Diseases, Ninth Revision, Clinical Modification (ICD-9-CM) codes 765.01-765.08 (Disorders relating to extreme immaturity of infant) or 765.11-765.18 (Disorders relating to other preterm infants). The ELBW subgroup, comprising newborns with birthweight less than $1000 \mathrm{~g}$, was identified using ICD9-CM codes 765.01 (Disorders relating to extreme immaturity of infant less than $500 \mathrm{~g}$ ), 765.02 (Disorders relating to extreme immaturity of infant 749-500 g), 765.03 (Disorders relating to extreme immaturity of infant less 999-750 g), 765.11 (Disorders relating to other preterm infants $500 \mathrm{~g}$ ), 765.12 (Disorders relating to other preterm infants 749-500 g), and 765.13 (Disorders relating to other preterm infants 999-750 g). All data from discharge forms with codes 765.00 or 765.10 for any diagnosis were excluded from the analysis because these could not be classified for birthweight.

Results were reported using a choropleth map as relative risk (RR) of hospitalization. The regional map showed cities, and the map of Taranto showed the municipal districts. To determine the RR, the average regional rate was applied to newborns in each district. For regional analysis, we used the population recorded by ISTAT (ISTAT 2020). For the analysis by district, we used the population from the Taranto Registry Office (TRO), which was georeferenced to the district area using batch geocoding (Batch Geocode Tool 2020) to overlay the information of residence location to the district area. To georeference birth events in Taranto, we applied two-step record linkage (RL). The first step was deterministic and consisted of a perfect match for each letter or figure in the identification code between the HDFDB and TRO. The second step was probabilistic (Fornari et al. 2008), based on the Fellegi and Sunter model (Fellegi and Sunter 1969). Additional runs of probabilistic RL were applied to unlinked records, changing the locking and comparison variables each time. The choice of false positive and false negative threshold values in the probabilistic procedures was carried out by means of sensitivity analysis. In case of a change in residence, a weight was given to the time spent in a specific area, determined as the percentage of time spent with respect to the total time of the survey for a specific subject.

RR was estimated using the Besag-York-Molliè (BYM) Bayesian model (Besag et al. 1991), adjusted for the deprivation index. The deprivation index, which is an adjustment variable in the model, depends on five indicators: low level of education, unemployment, non-home ownership, one parent family, and overcrowding (Caranci et al. 2010). To smooth RR in the structured component of the BYM model, we used an adjacency matrix. To smooth the RR of cities in the regional maps, we used the matrix for neighboring municipalities. Expected cases for each geographical area were determined by indirect standardization, using regional rates of the Puglia region as reference.

Results were reported as RR and 95\% uncertainty interval (UI), given by the 2.5th and 97.5 th percentile of the Bayesian model. The model was run with a burn-in of 
10,000 simulations and a total of 30,000 simulations. If the UI included 1, the RR was considered not statistically significant.

Record linkage and standardization to determine the expected number of events were performed using SAS version 9.4 (SAS Institute, Inc., Cary, NC, USA) (SAS Institute 2011). The BYM model was run using WinBUGS 1.4 (Lunn et al. 2000). Maps were generated with QGIS version 2.8.2 (Environmental Protection Regional Agency Apulia 2019).

\section{Results}

From 2001 to 2013 , there were 492,537 live births, including 252,899 (51.3\%) male and 239,638 (48.7\%) female infants. Among these, 16,265 (7,949 (48.9\%) male and 8,316 $(51.1 \%)$ female infants) were immature preterm (LBW). In the same period, there were $1,342(645(48.1 \%)$ male and 697 (51.9\%) female) ELBW newborns. In Taranto, there were 22,582 live births, 11,636 (51.5\%) male and 10,946, (48.5\%) female infants. Among these, 1,113 were LBW (564 (49.1\%) male and 567 (50.9\%) female), among which 46 were ELBW ( 23 male and 23 female). In the analysis by district, a total of $215 \mathrm{HDF}$ records were lost owing to failure of record linkage between the HDFDB and TRO or unsuccessful georeferencing.

The time series for the raw rate of LBW and ELBW in the entire region (Fig. 1) did not show a specific trend or cycle. Regional rates (Fig. 1a) for LBW infants increased from 26.9 per 1000 live births in 2001 to 30.2 per 1000 live births in 2013. Rates of LBW in Taranto (Fig. 1a) in these years were consistently high, from 41.6 per 1000 live births in 2001 to 42 per 1000 live births in 2013 with a peak in 2003 with a rate of 82.3 per 1000 live births. Regional rates for ELBW infants (Fig. 1b) changed from 2.0 per 1000 live births in 2001 to 2.2 per 1000 live births in 2013. There was an increase in 2004 with 4.1 per 1000 live births and in 2006 with 3.9 per 1000 live births, but rates decreased to the usual level in the following years. The rates for Taranto showed a peak in 2002 and in 2005, respectively 4.7 and 4.6 per 1000 live births, but they decreased to 2.4 per 1000 live births in 2007 and then remain lower than 2.0 per 1000 live births from 2008 until 2013 when the rate was 1.2 per 1000 live births.

The cities with higher RRs for LBW were on the east coast (Fig. 2a) in the vicinity of Brindisi and up to Lecce, with rates in the class $1.2-1.4$ per 1000 live births, which were statistically significant. The highest rate in the region was in Taranto where the RR of LBW was 1.47 (95\% UI $1.38-1.56)$.

In the northern and southeast regions between the cities of Brindisi and Lecce, some municipalities had high and statistically significant RRs for LBW, but there were no significant clusters. There were no other areas with $R R>1$.

The risk of hospitalization for ELBW infants appeared equally distributed across the whole regional territory, and there were no clusters of municipalities with particularly high RRs (Fig. 2b). The only municipalities with a significant RR for ELBW were Bari (1.89, UI 1.64-2.17) and some neighboring municipalities. In the very southern limit of the region, a group of city areas with RR $>1$ for ELBW was observed, but these were all non-significant.

Figure 3a shows that all districts had a very high and statistically significant RR of LBW events, with RRs ranging from 1.24 (95\% UI 1.1-1.4) for Tamburi district to 1.47 (95\% CI 1.2-1.8) for San Vito District. Analysis of the geographical distribution of RRs for ELBW in Taranto did not show patterns of significantly high RRs (Fig. 3b).

\section{Discussion}

The results of the present survey showed a clear geographical pattern of RRs for LBW and ELBW. Higher RRs were observed near cities with high environmental risk owing to the presence of a carbon power plant (Brindisi), and a petroleum refinery and one the largest steel manufacturing facilities in Europe (Taranto). The environmental pollution in these areas requires greater attention, with respect to evaluation of the health of the resident population. In particular, newborn and pregnant women are more sensitive to the negative health effects of environmental pollution.

This survey was conducted using current information sources like the HDFDB, one of the most reliable and complete resources of health-related information after registries such as the Cancer Registry and Death Cause Registry. As a data source for pregnancy and births, the Delivery Certificate can provide detailed information about mothers and newborns. However, these records are incomplete as only events occurring in a particular health district are recorded; information about residents hospitalized outside the district is not included on the certificate.

Electronic health databases, rather than ad hoc studies, are often used to determine risk; these include electronic clinical records (Nobles et al. 2019; Seabrook et al. 2019), birth certificates (Xuea et al. 2018) or data from national statistical institutes. Many studies select events according to ICD-9 or ICD-10 codes. However, prospective or cohort studies are more appropriate for evaluating RRs of environmental exposure; otherwise, it is difficult to properly determine the duration and degree of exposure and the possible relationship with birth and pregnancy outcomes (Nie et al. 2018).

In evaluating the association between location of residence and pollution source, it is necessary to evaluate the 

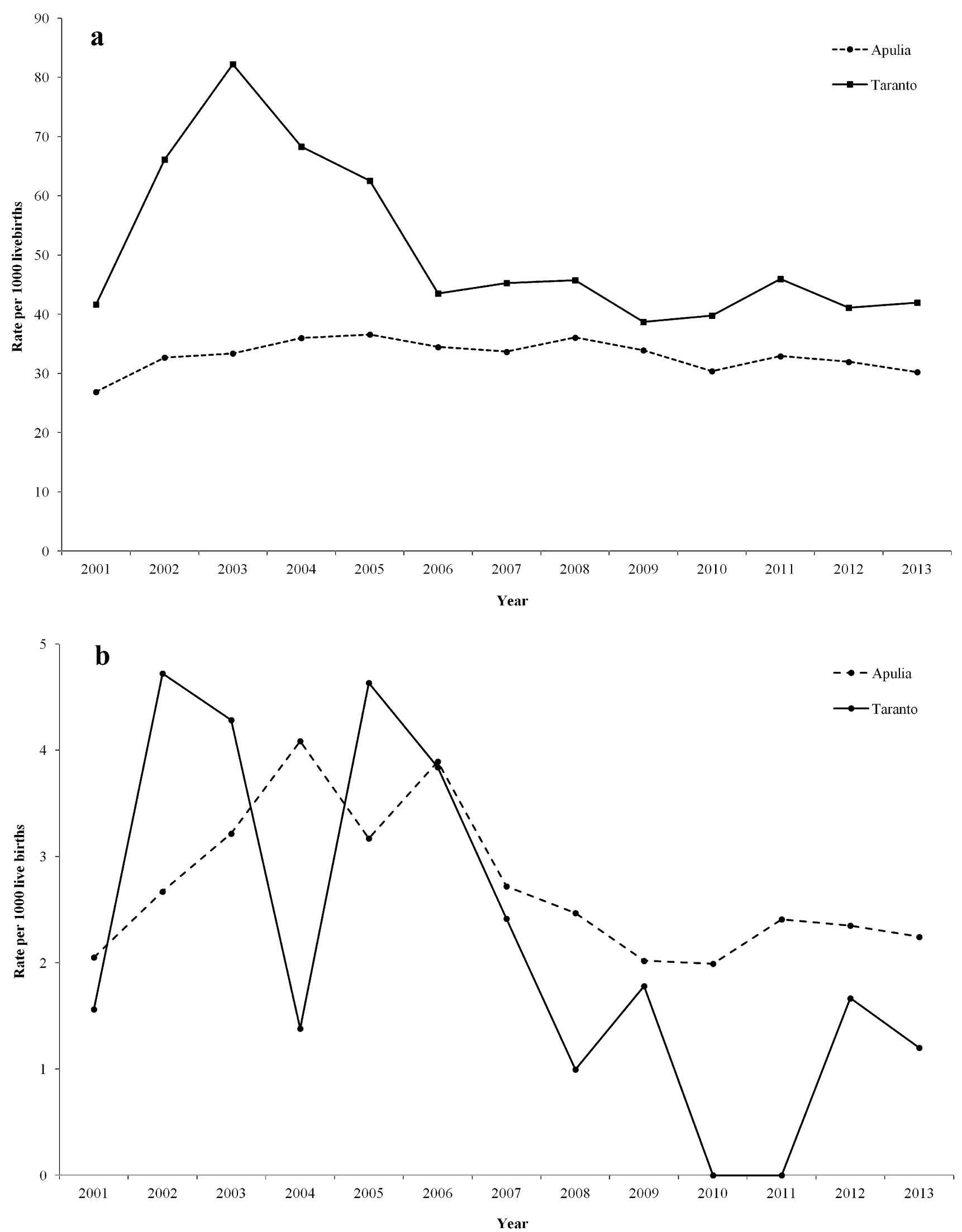

Fig. 1 Time series of raw rate of preterm immature birth per 1000 live births. a Time series of low birthweight (LBW); b time series of extremely low birthweight (ELBW) 
a

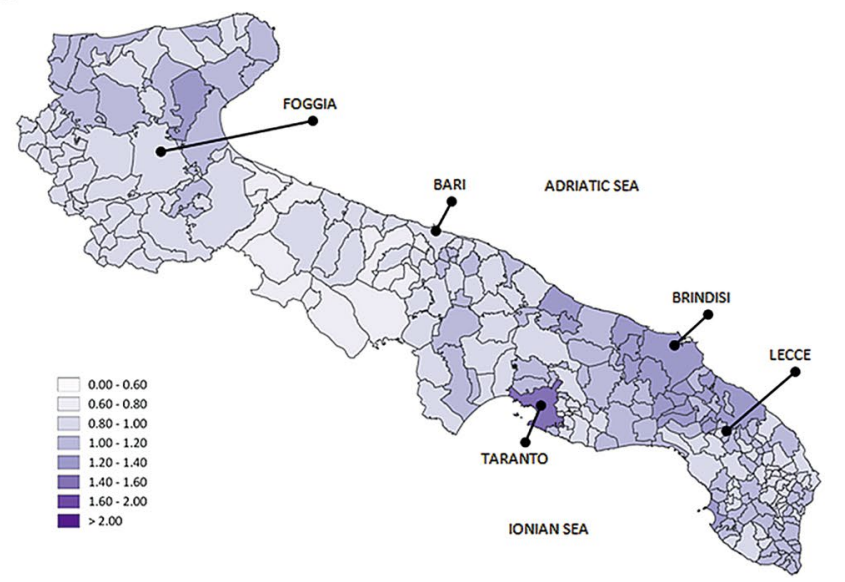

b

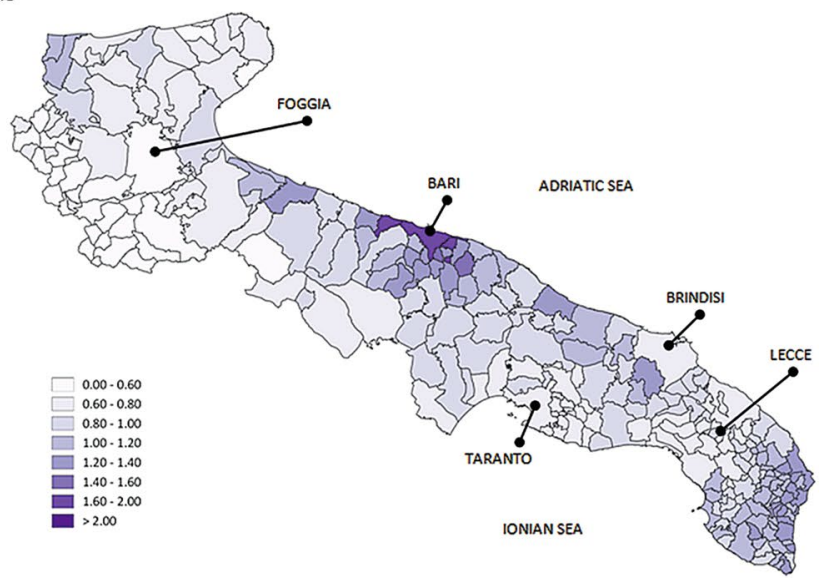

Fig. 2 Geographical distribution of relative risk for a low birthweight (LBW); and b extremely low birthweight (ELBW) newborns in Apulia

$\mathbf{a}$

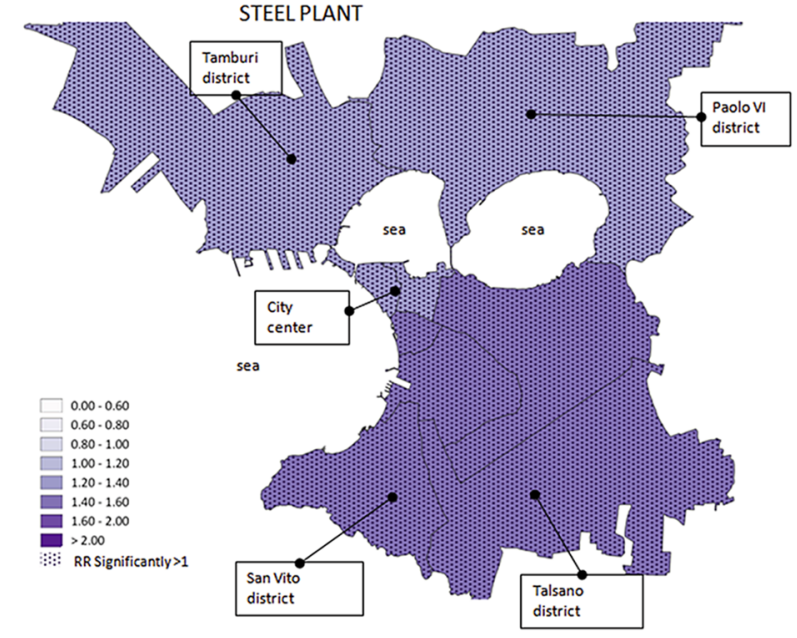

b

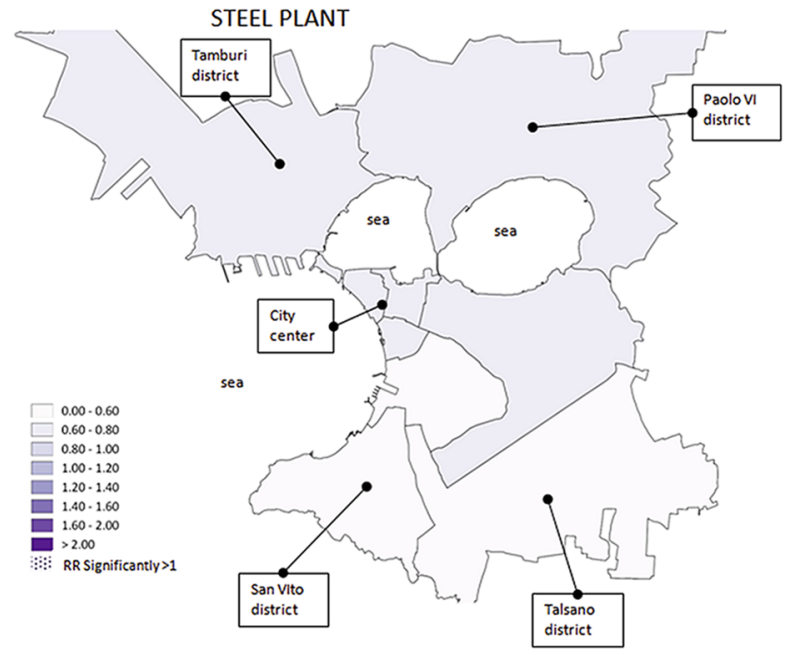

Fig. 3 Geographical distribution of relative risk for a low birthweight (LBW); and b extremely low birthweight (ELBW) in Taranto, by municipal district

possible causative role of environmental pollution in health outcomes. Prospective studies are most appropriate for this purpose. An example of such studies is Project Viva, in which the authors have conducted accurate evaluation of traffic pollution exposure and residence; however, their study findings were inconclusive (Fleisch et al. 2019).

In this study, we used the Municipal Office Registry to assess residence location and we accounted for changes in residence, although we did not include information regarding distance of residence from pollution sources. We observed however higher RRs of ELBW and LBW in areas near industrial facilities in the city of Taranto. When distance from the source of pollution is entered into the model and individual data are georeferenced, regression analysis can be used to estimate the effect of the pollution source versus the outcome of interest. Published findings have confirmed an association between LBW and air pollution (Arroyoa et al. 2019; Gong et al. 2018), even using different methods of statistical analysis (Arroyoa et al. 2019).

The duration of exposure was not included in our model. However, many people were exposed for the entire period of observation as they have lived in Apulia or Taranto since childhood. Many studies have evaluated the length of exposure using the duration of pregnancy or by trimester of pregnancy. A population-based study conducted in Scotland used accurate anthropometric measurements and growth indices of the fetus as well as repeated ultrasound scans and found a possible association with environmental pollution, although mother's smoking was a confounding factor in that study (Clemens et al. 2017). 
In our study, the rates of ELBW and LBW for the whole region of Apulia were similar to reports from developed countries with high-quality health services. The area of Taranto is a unique situation, given the high concentration of industrial plants close to urban areas, and it is conceivable that environmental pollution is a significant risk factor for the health of people living in that area. In our study, we could not determine the RR for specific environmental exposures adjusted for other risk factors or confounding factors. Other authors have accounted for the mother's health-related habits in considering the role of environmental pollution (Kihal-Talantikite et al. 2017; Shah et al. 2011; Stieb et al. 2012). The authors of such studies concur that further investigation is warranted as much remains unknown regarding the true risk for LBW and ELBW outcomes in environmentally high-risk areas.

In our survey, we did not observe a particular geographic distribution of ELBW, so it was not possible to identify an association of environmental pollution effects on this outcome. A previous study in Taranto evaluated aerial maps of the distribution of pollutants above the city, discriminating between industrial emissions and other sources; the authors compared the maps with the distribution of diseases (Mincuzzi et al. (2013)). The authors thus provided evidence supporting an association between environmental pollution and residence location of people with various diseases, especially lung cancer and childhood cancers (Mincuzzi et al. 2013). The maps in that study suggested an association of $\mathrm{PM}$ with diameter $<2.5 \mu \mathrm{m}(\mathrm{PM} 2.5)$ and $\mathrm{NO}_{2}$ with these diseases. Published studies have reported various outcomes related to these pollutants; $\mathrm{O}_{3}$ and PM 2.5 have been found to be related to IUGR (Clemens et al. 2017; Nobles et al. 2019) and PM2.5 and sulfur oxides have been shown to be associated with LBW (Xuea et al. 2018). These results suggest an association, but strong evidence of an association is lacking; one meta-analysis had high levels of heterogeneity, indicating that robust multicenter prospective studies are needed to resolve this question (Stieb et al. 2012).

\section{Conclusions}

The findings of this survey highlight a significant risk of preterm LBW newborns in environmentally compromised areas of southern Italy. In cities with the greatest presence of industry, we found an increased risk of LBW. These results confirm the possible harm to newborns and adverse pregnancy outcomes related to environmental pollution, although we were unable to determine causation.

Acknowledgements We thank Analisa Avila, ELS, of Edanz Group (www.edanzediting.com/ac) for editing a draft of this manuscript.
Author contributions Conceptualization: ASM, AM and PT; methodology: NB, SL and GS; software: ST and NB; validation: SL and NB; formal analysis: NB, SL and PT; data curation: NB, ST and PT; writing-original draft preparation: $\mathrm{PT}$ and $\mathrm{NB}$; writing-review and editing: GS, ASM and AM; supervision: GS and ASM; funding acquisition: ASM and AM.

Funding Open access funding provided by Università degli Studi di Bari Aldo Moro within the CRUI-CARE Agreement. This research was funded by Regione Puglia, Center for Health and Environment.

Code availability Software code is only available upon request.

\section{Compliance with Ethical Standards}

Conflict of interest The authors declare no conflict of interest.

Open Access This article is licensed under a Creative Commons Attribution 4.0 International License, which permits use, sharing, adaptation, distribution and reproduction in any medium or format, as long as you give appropriate credit to the original author(s) and the source, provide a link to the Creative Commons licence, and indicate if changes were made. The images or other third party material in this article are included in the article's Creative Commons licence, unless indicated otherwise in a credit line to the material. If material is not included in the article's Creative Commons licence and your intended use is not permitted by statutory regulation or exceeds the permitted use, you will need to obtain permission directly from the copyright holder. To view a copy of this licence, visit http://creativecommons.org/licenses/by/4.0/.

\section{References}

Almond D, Chay KY, Lee DS (2004) The costs of low birth weight, NBER Working Paper, JEL No. 10552, H51, I12, I18

Arroyoa V, Díaza J, Salvadorc P, Linares C (2019) Impact of air pollution on low birth weight in Spain: an approach to a National Level Study. Environ Res 171:69-79

Basili F, Messia I, Montorio V, Tamburini C (2018) Delivery Certificate. The analysis of birth events. Year 2015. General Direction of Informatization of Health Information System and Statistics, Ed. Ministry of Health, Rome. www.salute.gov.it/statistiche

Batch Geocode Tool (2020) Map developers. https://www.mapdevelop ers.com/batch_geocode_tool.php

Besag J, York J, Molliè A (1991) Bayesian image restoration, with applications in spatial statistics. AISM 43:1-59

Caranci N, Biggeri A, Grisotto L, Paceli B, Spadea T, Costa G (2010) The Italian deprivation index at census block level: definition, description and association with general mortality. Epidemiol Prev 34(4):167-176

Cavallo MC, Gugiatti A, Fattore G, Gerzeli S, Barbieri D, Zanini $\mathrm{R}$, on behalf of the Neonatal Adequate Care for Quality of Life (NEO-ACQUA) Study Group (2015) Cost of care and social consequences of very low birth weight infants without prematurerelated morbidities in Italy. Ital J Pediatr 41:59

Clemens T, Turner S, Dibben C (2017) Maternal exposure to ambient air pollution and fetal growth in North-East Scotland: a population-based study using routine ultrasound scans. Environ Int 107:216-226

Development Team (2014) QGIS Geographic Information System. Open Source Geospatial Foundation Project. https://qgis.osgeo .org 
Environmental Protection Regional Agency Apulia (2019) Annual relation on Apulia air quality. https://www.arpa.puglia.it/web/guest/ rapporti_annuali_qa

Fellegi IP, Sunter A (1969) A theory of record linkage. JASA 64:1183-1210

Fleisch AF, Aris IM, Rifas-Shiman SL, Coull BA, Luttmann-Gibson H, Koutrakis P, Schwartz JD, Kloog I, Gold DR, Oken E (2019) Prenatal exposure to traffic pollution and childhood body mass index trajectory. Front Endocrinol 9:771. https://doi.org/10.3389/ fendo.2018.00771

Fornari C, Madotto F, Demaria M, Romanelli A, Pepe P, Raciti M, Tancioni V, Chini F, Trerotoli P, Bartolomeo N, Serio G, Cesana G, Corrao G (2008) Record-linkage procedures in epidemiology: an Italian multicentre study. Epidemiol Prev 323(Suppl):79-88

Gong X, Bell LY, ML, Zhan FB, (2018) Association between maternal residential proximity to air emissions from industrial facilities and low birth weight in Texas, USA. Environ Int 120:181-198

ISTAT (2020) Resident population databases. https://demo.istat.it/

Kihal-Talantikite W, Zmirou-Navier D, Padilla C, Deguen S (2017) Systematic literature review of reproductive outcome associated with residential proximity to polluted sites. Int J Health Geogr 16:20

Lee ACC, Kozuki N, Cousens S, Stevens GA, Blencowe H, Silveira MF et al (2017) Estimates of burden and consequences of infants born small for gestational age in low and middle income countries with INTERGROWTH-21st standard: analysis of CHERG datasets. BMJ 358:j3677

Lunn DJ, Thomas A, Best N, Spiegelhalter D (2000) WinBUGS-a Bayesian modelling framework: concepts, structure, and extensibility. Stat Comput 10:325-337

Mataloni F, Stafoggia M, Alessandrini E, Triassi M, Biggeri A, Forastiere F (2012) Studio di coorte sulla mortalità e morbosità nell'area di Taranto. Epidemiol Prev 36(5):237-252

Mincuzzi A, Minerba S, Trerotoli P, Bartolomeo N, Serio G, Tafuri S, Germinario G, Serinelli M, Morabito A, Spartera M, Giua R,
Assennato G (2013) IESIT: Indagine Epidemiologica Sito inquinato di Taranto. CLIO EDU, Lecce ((ISBN: 978-88-96646-42-7))

Minerba S, Mincuzzi A, Leogrande S, Serio G, Trerotoli P, Bartolomeo N et al (2018) Le mappe della salute a Taranto. Risultati dell'indagine IESIT II. Minigraf Ed., Lecce (ISBN 978-88-8933323-5)

Nie J, Li J, Cheng L, Li Y, Deng Y, Yan Z, Duan L, Niu Q, Perera F, Tang D (2018) Maternal urinary 2-hydroxynaphthalene and birth outcomes in Taiyuan, China. Environ Health 17:91

Nobles CJ, Grantz KL, Liub D, Williams A, OuidirM (2019) Physician diagnosis of fetal growth restriction versus population-based small-for-gestational age. In: Seeni I, Sherman S, Mendola P (ed) Ambient air pollution and fetal growth restriction. Science of the total environment, vol 650, pp 2641-2647

O'Leary M, Edmond K, Floyd S, Newton S, Thomasd G, Thomas SL (2017) A cohort study of low birth weight and health outcomes in the first year of life, Ghana. Bull World Health Organ 95:574-583

SAS Institute (2011) The SAS system for Windows. Release 9.4. SAS Inst., Cary

Seabrook JA, Smith A, Clark AF, Gilliland JA (2019) Geospatial analyses of adverse birth outcomes in Southwestern Ontario: examining the impact of environmental factors. Environ Res 172:18-26

Shah PS, Balkhair T, on behalf of Knowledge Synthesis Group on Determinants of Preterm/LBW births (2011) Air pollution and birth outcomes: a systematic review. Environ Int 37:498-516

Stieb DM, Chen L, Eshoul M, Judek S (2012) Ambient air pollution, birth weight and preterm birth: a systematic review and metaanalysis. Environ Res 117:100-111

United Nations (2004) Children's Fund and World Health Organization, Low: country, regional and global estimates. UNICEF, New York (ISBN: 92-806-3832-7)

Xuea T, Zhua T, Han Y (2018) Association between birthweight and ambient PM2.5 in the United States: Individually-varied susceptibility and spatial heterogeneity. Environ Int 119:388-397 